\title{
Dielectric and frequency-dependent transport properties of lanthanum-doped bismuth ferrite
}

\author{
A. K. Sahu* ${ }^{* \ddagger}$, S. K. Satpathy ${ }^{\dagger}$ and Banarji Behera*, ${ }^{*}$ \\ *School of Physics, Sambalpur University, JyotiVihar \\ Burla 768019, Odisha, India \\ ${ }^{\dagger}$ Centurion University of Technology and Management \\ Odisha, India \\ ${ }^{\ddagger} A k s h y a y a 62 @$ gmail.com \\ §anarjibehera@gmail.com
}

Received 3 July 2019; Revised 2 August 2019; Accepted 12 August 2019; Published 12 September 2019

\begin{abstract}
Polycrystalline samples of $\mathrm{Bi}_{1-x} \mathrm{La}_{x} \mathrm{FeO}_{3}[x=0.5,0.6,0.7$ and 0.8$]$ were synthesized through high temperature solid state reaction method. The structural studies of the compounds were done using X-ray diffraction technique. Dielectric constant and dielectric loss were studied for various frequencies $\left(100 \mathrm{~Hz}-10^{4} \mathrm{~Hz}\right)$ at different temperatures. The temperature-dependent non-Debye type relaxation process was suggested in the materials from the analysis of frequency-dependent electrical data at different temperatures. Temperature dependence of $\mathrm{dc}$ and ac conductivity at various frequencies showed negative temperature coefficient of resistance (NTCR) behavior. The frequency dependence of ac conductivity at different temperatures obeyed Jonscher's universal power law. The temperature dependence of $\mathrm{dc}$ and ac conductivity was fitted to Arrhenius equation. The activation energies at different temperature ranges were calculated to know the charge species involved in the conduction process.
\end{abstract}

Keywords: Solid state reaction; XRD; impedance; electrical conductivity.

\section{Introduction}

Recently, it is taking great attention that multiferroic material shows the electric and magnetic ordering due to the design of multifunctional devices used in the information storage, sensors and spintronics. ${ }^{1,2}$ In multiferroics, ferromagnetism and ferroelectricity co-exist simultaneously. Bismuth ferrite (BFO) is a prominent material because of its excellent ferroelectric properties. It also exhibits ferroelectrics and ferromagnetism simultaneously. Again, the structure and properties of $\mathrm{BFO}$ are connected with the magneto electrics, i.e., the compound processing both magnetic (spin) and electric dipole long-range ordering. ${ }^{3} \mathrm{BFO}$ is the most typical and extensively investigated representative of this class of material. ${ }^{4}$

Simultaneous presence of ferroelectricity and anti-ferromagnetic order with weak ferromagnetism ${ }^{5,6}$ at room temperature is the one of the salient features of $\mathrm{BiFeO}_{3}$. A rhombohedral structure confirms by the good agreement of lattice parameter and suggests a very weak ferroelectric loop with low remanent polarization. ${ }^{7}$ The preparation of single phase $\mathrm{BiFeO}_{3}$ is a challenging problem for researchers. The formation of $\mathrm{BiFeO}_{3}$ by the addition of different percentages of La has been reported by Kumar et al. ${ }^{8}$ In this work, the structural, microstructural, and electrical properties of $\mathrm{Bi}_{1-x} \mathrm{La}_{x} \mathrm{FeO}_{3}[x=0.5,0.6,0.7$ and 0.8$]$ have been studied systematically.

\section{Experimental Details}

$\left(\mathrm{Bi}_{1-x} \mathrm{La}_{x} \mathrm{FeO}_{3}\right)[x=0.5,0.6,0.7$ and 0.8$]$ were prepared by solid state reaction technique. It was prepared with high purity ingredients, i.e., $\mathrm{Bi}_{2} \mathrm{O}_{3}, \mathrm{Fe}_{2} \mathrm{O}_{3}$ and $\mathrm{La}_{2} \mathrm{O}_{3}$ in a suitable stoichiometry. The oxides were thoroughly mixed; first in air atmosphere for $2 \mathrm{~h}$, and then in alcohol for $1 \mathrm{~h}$. The mixed powders were calcined at an optimized temperature of $800^{\circ} \mathrm{C}$ for $5 \mathrm{~h}$. The calcined powder was cold pressed into cylindrical pellets of $10 \mathrm{~mm}$ diameter and $1-2 \mathrm{~mm}$ thickness at a pressure of $3.5 \times 10^{6} \mathrm{~N} / \mathrm{m}^{2}$ using a hydraulic press. PVA (polyvinyl alcohol) was used as binder to reduce the brittleness of the pellet, which burnt out during the sintering. Then the pellets were sintered at $850^{\circ} \mathrm{C}$ for $6 \mathrm{~h}$ in an air atmosphere. The formation and quality of the compound was studied by an $\mathrm{X}$-ray diffraction (XRD) technique at room temperature with a powder diffractometer (Rigaku, Ultima IV) using $\mathrm{CuK}_{\alpha}$ radiation $(\lambda=1.5405 \AA)$ in a wide range of Bragg's angles $2 \theta\left(20^{\circ} \leq 2 \theta \leq 80^{\circ}\right)$ with a scanning rate of $3 \% \mathrm{~min}$. To study the electrical properties of the materials, the sintered pellets were electroded with air-drying conducting silver paste. After electroding, the pellets were dried at $150^{\circ} \mathrm{C}$ for $4 \mathrm{~h}$ to remove the remaining moisture and then were cooled to room temperature before taking any measurement. The impedance measurements were carried out using an LCR meter (HIOKI, Model 3532) at a frequency range of $10^{2}-10^{6} \mathrm{~Hz}$ from $25-450^{\circ} \mathrm{C}$.

This is an Open Access article published by World Scientific Publishing Company. It is distributed under the terms of the Creative Commons Attribution 4.0 (CC BY) License which permits use, distribution and reproduction in any medium, provided the original work is properly cited. 


\section{Result and Discussion}

\subsection{Structural properties}

Figure 1 shows the XRD pattern of $\mathrm{Bi}_{1-x} \mathrm{La}_{x} \mathrm{FeO}_{3}[x=0.5$, $0.6,0.7$ and 0.8 ] at room temperature. Analysis of these XRD pattern reveals the presence of the $\mathrm{Bi}_{1-x} \mathrm{La}_{x} \mathrm{FeO}_{3}[x=0.5$,

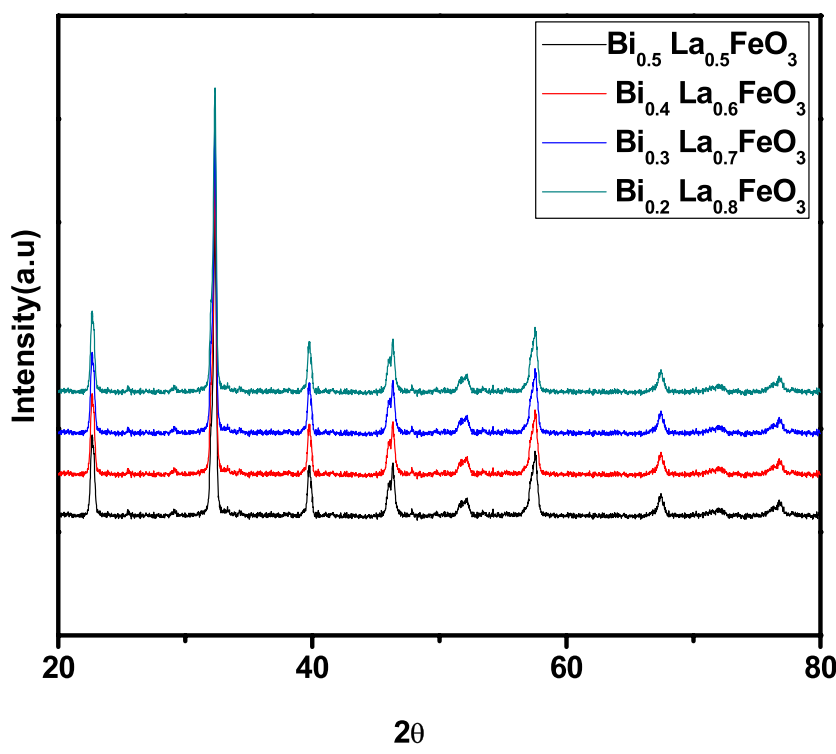

Fig. 1. XRD pattern of $\mathrm{Bi}_{1-x} \mathrm{La}_{x} \mathrm{FeO}_{3}[x=0.5,0.6,0.7$ and 0.8$]$ at room temperature.
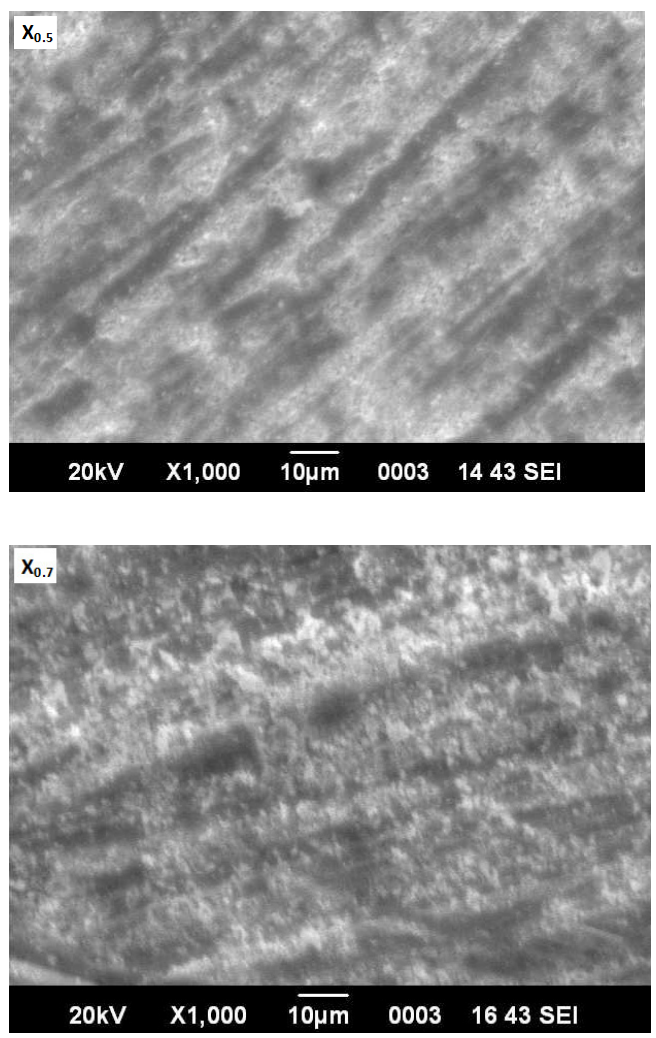

0.6, 0.7 and 0.8] with an orthorhombic phase for all the materials. ${ }^{9}$ All the diffraction peaks within $25^{\circ}-30^{\circ}$ can be perfectly indexed as the orthorhombic structure of bulk $\mathrm{Bi}_{2} \mathrm{Fe}_{4} \mathrm{O}_{9}$. This may be due to the impurities of phase such as $\mathrm{Bi}_{24} \mathrm{FeO}_{39}$ and $\mathrm{Bi}_{2} \mathrm{Fe}_{4} \mathrm{O}_{9}$ and they are thermodynamically stable phases at high temperatures. ${ }^{10-12}$ The crystallite size $(P)$ was roughly estimated from the broadening of a few XRD peaks (in a wide $2 \theta$ range) using the Scherrer's equation $P=K \lambda /\left(\beta_{1 / 2} \cos \theta_{h k l}\right),{ }^{13}$ (where $K=$ constant $=0.89, \lambda=$ $1.5405 \AA$ and $\beta_{1 / 2}=$ peak width of the reflection at half intensity). The average value of $P$ for all the materials is found to be in the range of $26 \mathrm{~nm}$.

\subsection{Microstructural properties}

Figure 2 shows the SEM micrographs of the sintered pellet. The nature of the microstructure indicates that the grains are densely packed over the surface of the materials. There is no change in the grains with the increase in the lanthanum concentration. The observe micrographs looks hazy. Therefore, it is not possible to evaluate the average grain size of the materials.

\subsection{Dielectric study}

The dielectric constant $\left(\varepsilon_{r}\right)$ and loss tangent $(\tan \delta)$ of $\mathrm{Bi}_{1-x} \mathrm{La}_{x} \mathrm{FeO}_{3}[x=0.5,0.6,0.7$ and 0.8$]$ as a function of
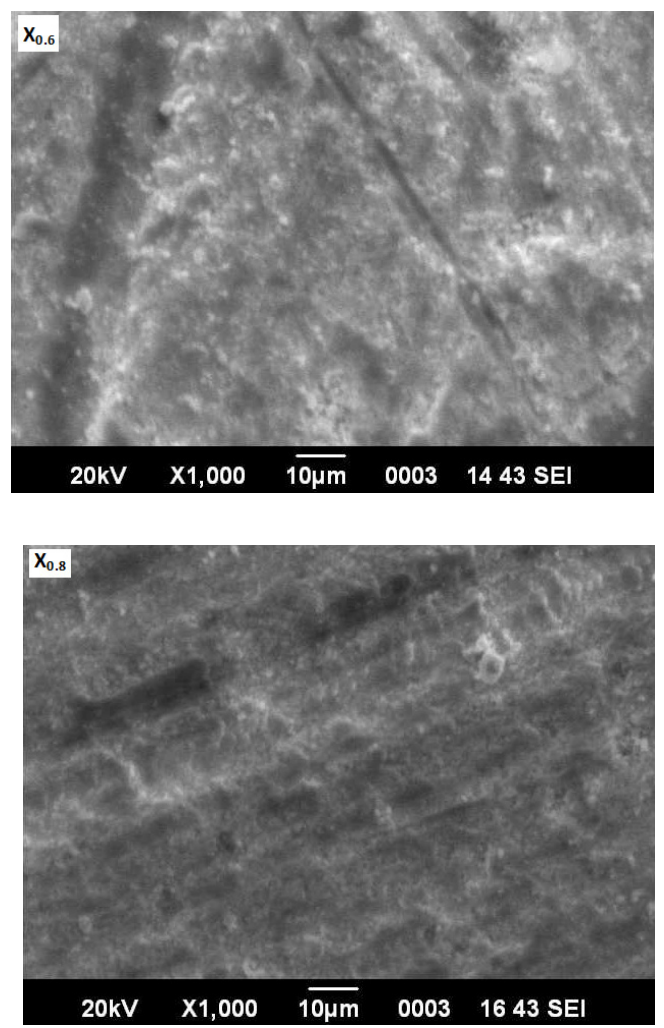

Fig. 2. Scanning electron microscope of $\mathrm{Bi}_{1-x} \mathrm{La}_{x} \mathrm{FeO}_{3}[x=0.5,0.6,0.7$ and 0.8$]$ at room temperature. 

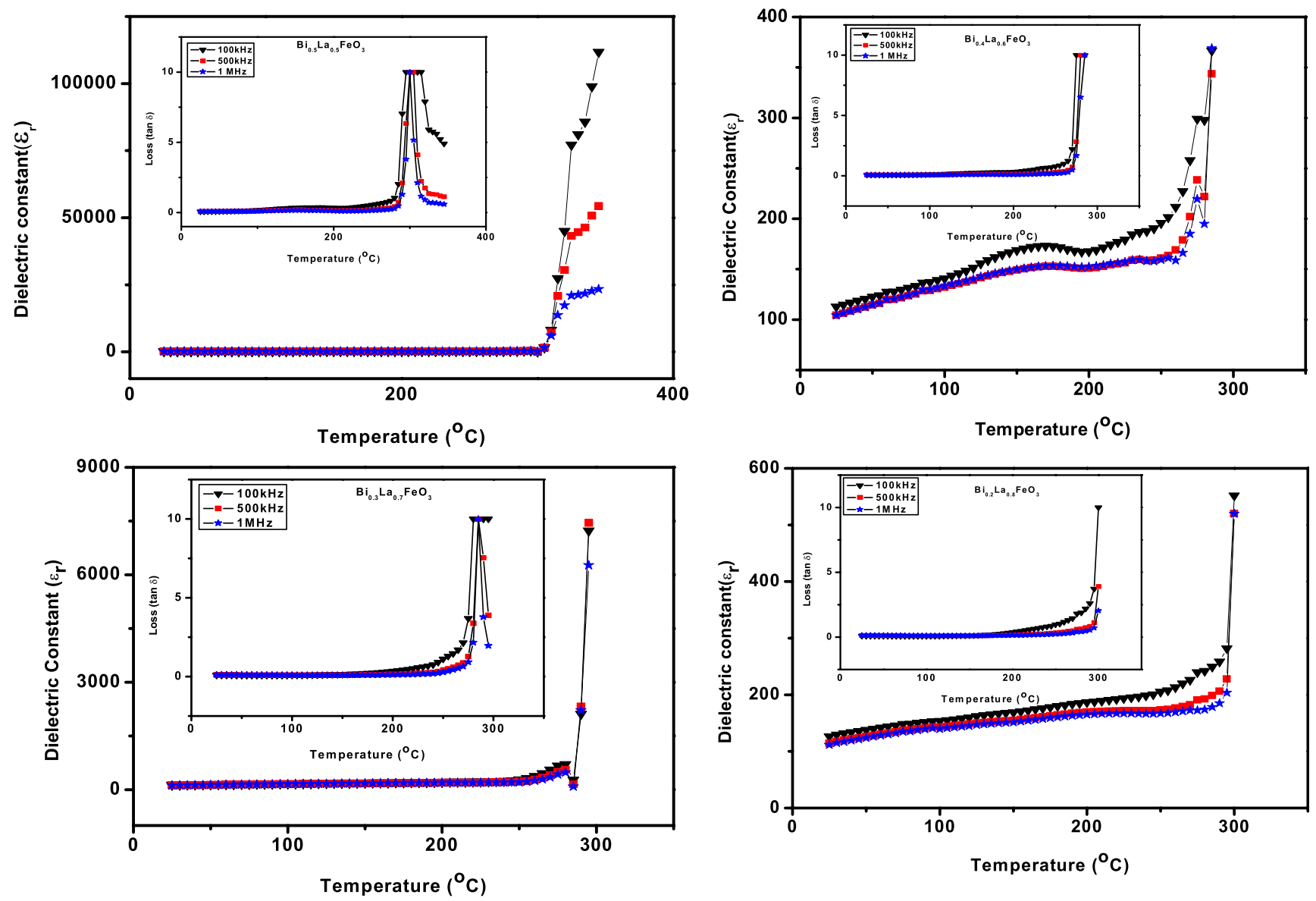

Fig. 3. Variation of dielectric constant $\left(\varepsilon_{r}\right)$ and dielectric loss ( $\tan \delta$ ) (inset) of $\mathrm{Bi}_{1-x} \mathrm{La}_{x} \mathrm{FeO}_{3}[x=0.5,0.6,0.7$ and 0.8$]$ with temperature at different frequencies.

temperature at different frequencies is shown in Fig. 3. It is observed that the dielectric constant of the samples exhibit lower values at low frequencies and high values at higher frequencies. The peak height at the transition temperature is observed to decrease with increase in frequency. ${ }^{14}$ The value of $\tan \delta$ increases on increasing temperature for all the compounds. It was observed that the value of $\tan \delta$ values increase with increase in lanthanum substitution. This increase in $\tan \delta$ may be due to enhancement in electrical conductivity and reduction in the ferroelectric domain's wall contribution.

\subsection{Impedance study}

Impedance spectroscopy is stated explicitly for the electrical measurement. This technique is more useful to separate the contributions of (i) bulk, (ii) grain boundary and (iii) electrode polarization effects of material. Electrical ac data of a material may be represented by any of the four basic formalisms which are correlated to each other. ${ }^{15}$ Compleximpedance: $Z^{*}=Z^{\prime}-j Z^{\prime \prime}=R-j / w C$, Complex admittance: $\quad Y^{*}=Y^{\prime}+j Y^{\prime \prime}=1 / R+j w C, \quad$ Complexmodulus:
$M^{*}=1 / \varepsilon^{*}=M^{\prime}+j M^{\prime \prime}=j w C_{0} Z$, Complex permittivity: $\varepsilon^{*}=\varepsilon^{\prime}-j \varepsilon^{\prime \prime}, \quad$ Losstangent, $\quad \tan \delta=\varepsilon^{\prime \prime} / \varepsilon^{\prime}=M^{\prime \prime} / M^{\prime}=$ $-Z^{\prime} / Z^{\prime \prime}=Y^{\prime} / Y^{\prime \prime}$.

Figure 4 shows the variation of real impedance $\left(Z^{\prime}\right)$ with frequency of $\mathrm{Bi}_{1-x} \mathrm{La}_{x} \mathrm{FeO}_{3}[x=0.5,0.6,0.7$ and 0.8$]$ at different temperatures. The entire curve merges at high-frequency region. This may be due to release of space charge polarization with rise in frequency. ${ }^{16}$ It is observed that the magnitude of $Z^{\prime}$ decreases with rise in temperature which shows negative temperature coefficient of resistance behavior. ${ }^{17}$ The frequency dependence of imaginary parts of impedance of $\mathrm{Bi}_{1-x} \mathrm{La}_{x} \mathrm{FeO}_{3}[x=0.5,0.6,0.7$ and 0.8$]$ is shown in Fig. 5. A peak is observed for all the concentrations. The peaks position shift toward the higher frequency region. This may be due to the temperature-dependent relaxation process and reduction in the bulk resistivity or may be due to small polaron hopping with reduction of electron-lattice coupling. ${ }^{18}$ The relaxation species may possibly be electrons or immobile species at lower temperature and defects at higher temperature that may be responsible for electrical conduction in the materials. ${ }^{19,20}$ As stated by Cao and Gerhardt ${ }^{21}$ the relaxation peak observed in $Z^{\prime \prime}$ plot is either related to short-range 

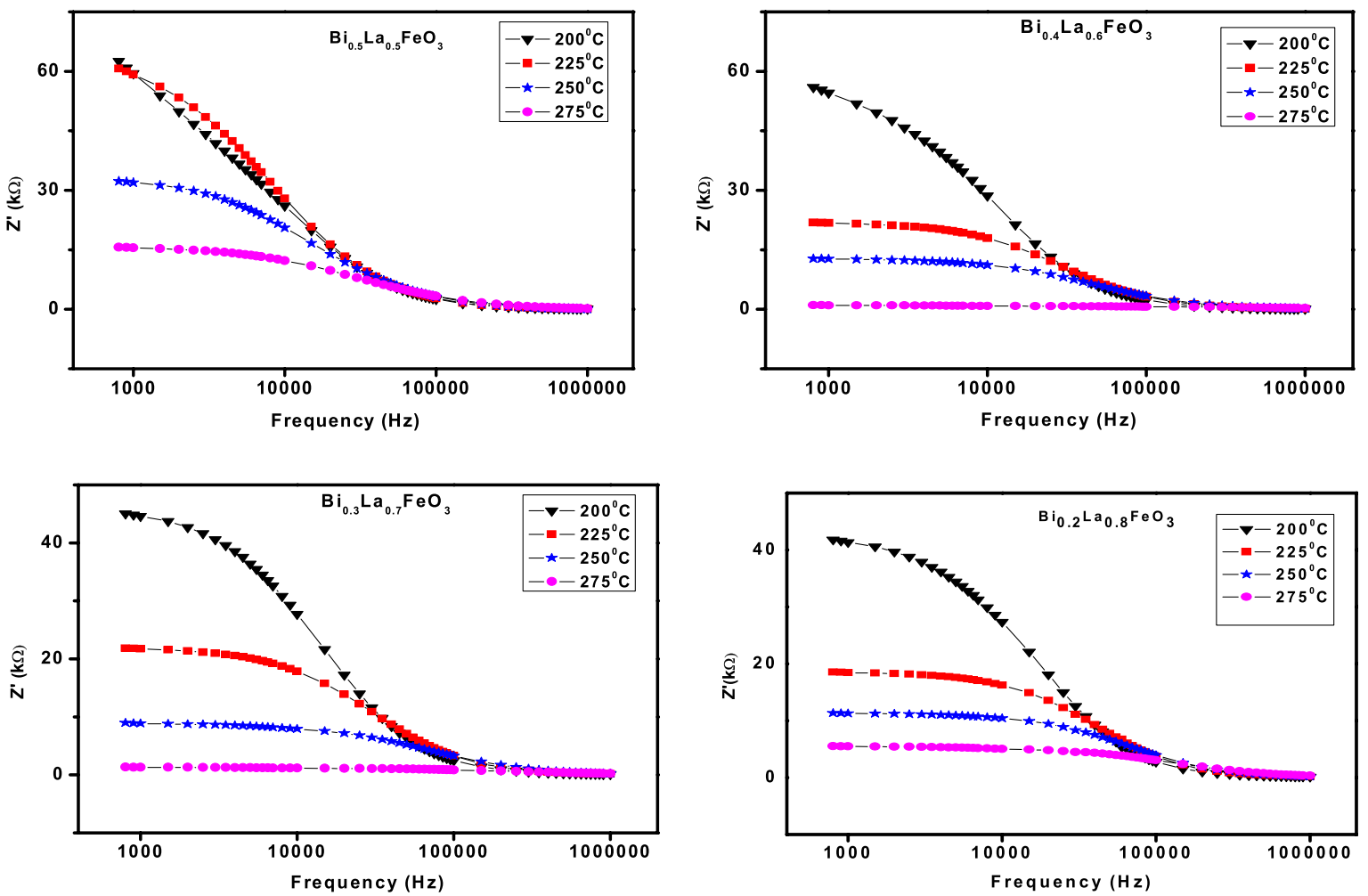

Fig. 4. Variation of $Z^{\prime}$ as a function of frequency of $\mathrm{Bi}_{1-x} \mathrm{La}_{x} \mathrm{FeO}_{3}[x=0.5,0.6,0.7$ and 0.8$]$ at different temperatures.
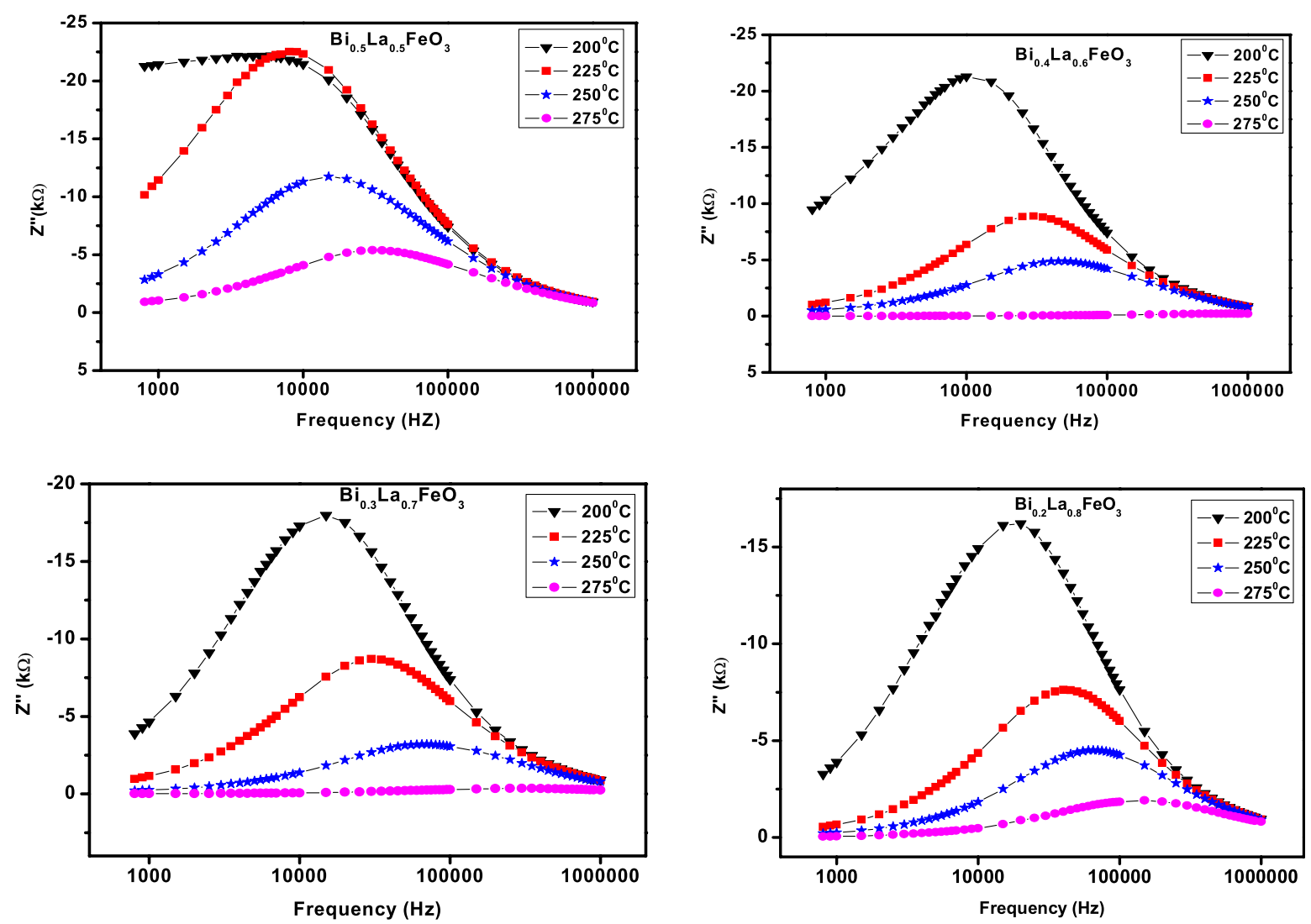

Fig. 5. Variation of $Z^{\prime \prime}$ as a function of frequency of $\mathrm{Bi}_{1-x} \mathrm{La}_{x} \mathrm{FeO}_{3}[x=0.5,0.6,0.7$ and 0.8$]$ at different temperatures. 

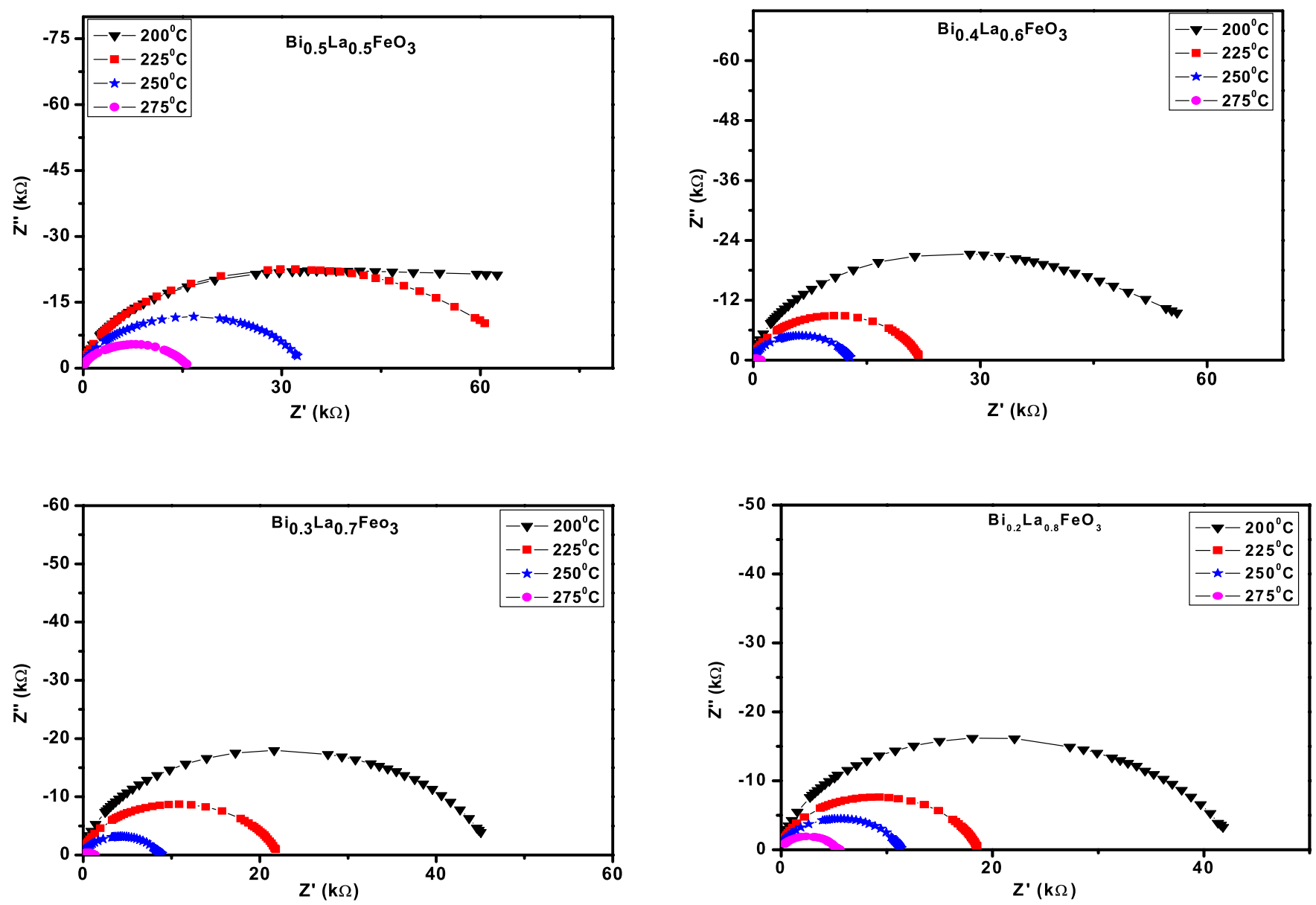

Fig. 6. Variation of complex impedance spectrum between $Z^{\prime}$ and $Z^{\prime \prime}$ of $\mathrm{Bi}_{1-x} \mathrm{La}_{x} \mathrm{FeO}_{3}[x=0.5,0.6,0.7$ and 0.8$]$ at selected temperatures.

hopping localized or long-range nonlocalized conduction mechanism.

Figure 6 shows the $Z^{\prime}$ versus $Z^{\prime \prime}$ of $\mathrm{Bi}_{1-x} \mathrm{La}_{x} \mathrm{FeO}_{3}$ $[x=0.5,0.6,0.7$ and 0.8$]$ at different temperatures. It consists of a single high-frequency arc with their center below the real axis. This high-frequency semicircle can be identified as a bulk property and the contribution of grain boundary effect seems to be eliminated.

The variation of $M^{\prime \prime}$ of $\mathrm{Bi}_{1-x} \mathrm{La}_{x} \mathrm{FeO}_{3}[x=0.5,0.6,0.7$ and 0.8] with frequency at different temperatures is shown in Fig. 7. The value of $M^{\prime \prime}$ increases to a maximum and then decreases with increase in frequency. The frequency where $M^{\prime \prime}$ reaches a maximum is called the relaxation frequency. The $M_{\max }^{\prime \prime}$ peak shifts toward higher-frequency side with rise in temperature. This behavior confirms the involvement of relaxation in the materials. In this process, the hopping of charge carriers mainly dominates. The temperature dependence of asymmetric broadening of the peak is observed which confirms the spread of relaxation with different time constants. Hence, the relaxation in the material is considered to be of non-Debye type. ${ }^{22}$

The scaling behavior of $\mathrm{Bi}_{1-x} \mathrm{La}_{x} \mathrm{FeO}_{3}[x=0.5,0.6,0.7$ and 0.8$]$ is studied by plotting $Z^{\prime \prime} / Z_{\max }^{\prime \prime}$ and $M^{\prime \prime} / M_{\max }^{\prime \prime}$ have been plotted with $\log _{10}\left(f / f_{\max }\right)$ at selected temperatures (Fig. 8). These plots are normally used to detect the presence of the smallest capacitance and the largest resistance as suggested by Sinclair et al. ${ }^{23}$ This will help to identify the relaxation process whether there is a short-range or longrange motion of charge carriers. The low-frequency side of the peak in $M^{\prime \prime} / M_{\max }^{\prime \prime}$ versus $\log _{10}\left(f / f_{\max }\right)$ curve represents the range in which the charge carriers can move over a long distance (i.e., charge carriers can perform successful hopping from one site to the neighboring site). In the high-frequency range, the charge carriers are spatially confined to their potential wells, and thus could make localized motions inside the well. The region where the peak occurs is an indicative of the transition from the long-range to the short-range mobility with increase in frequency. ${ }^{24}$

\subsection{Conductivity}

Figure 9 shows the frequency dependence of conductivity of $\mathrm{Bi}_{1-x} \mathrm{La}_{x} \mathrm{FeO}_{3}[x=0.5,0.6,0.7$ and 0.8$]$ with frequency at different temperatures. The AC conductivity is evaluated from the dielectric data by using the relation $\sigma_{\mathrm{ac}}=\omega \varepsilon_{0} \varepsilon_{r} \tan \delta$. All the conductivity graphs are well fitted 

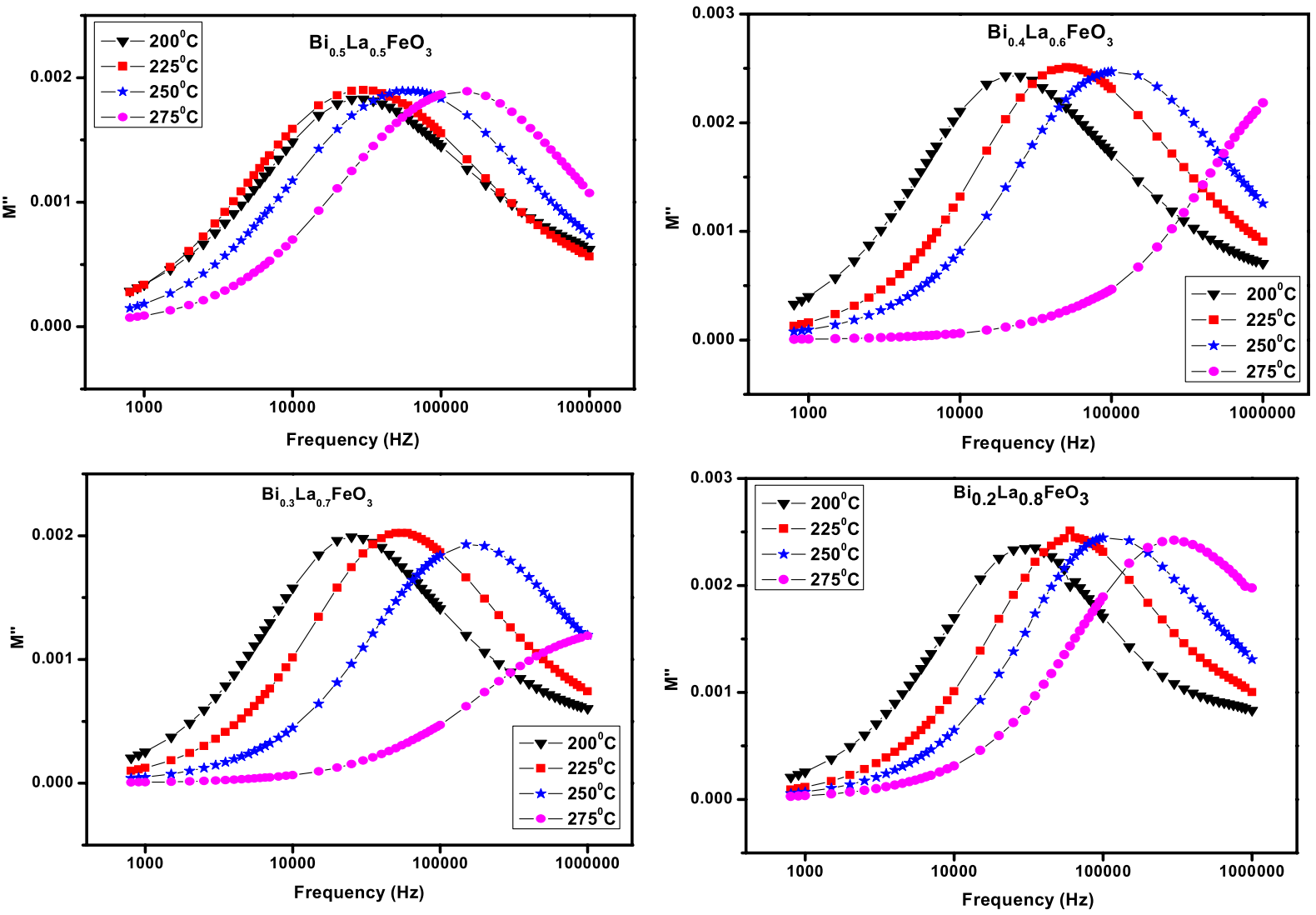

Fig. 7. Variation of $M^{\prime \prime}$ with frequency of $\mathrm{Bi}_{1-x} \mathrm{La}_{x} \mathrm{FeO}_{3}[x=0.5,0.6,0.7$ and 0.8$]$ at selected temperatures.
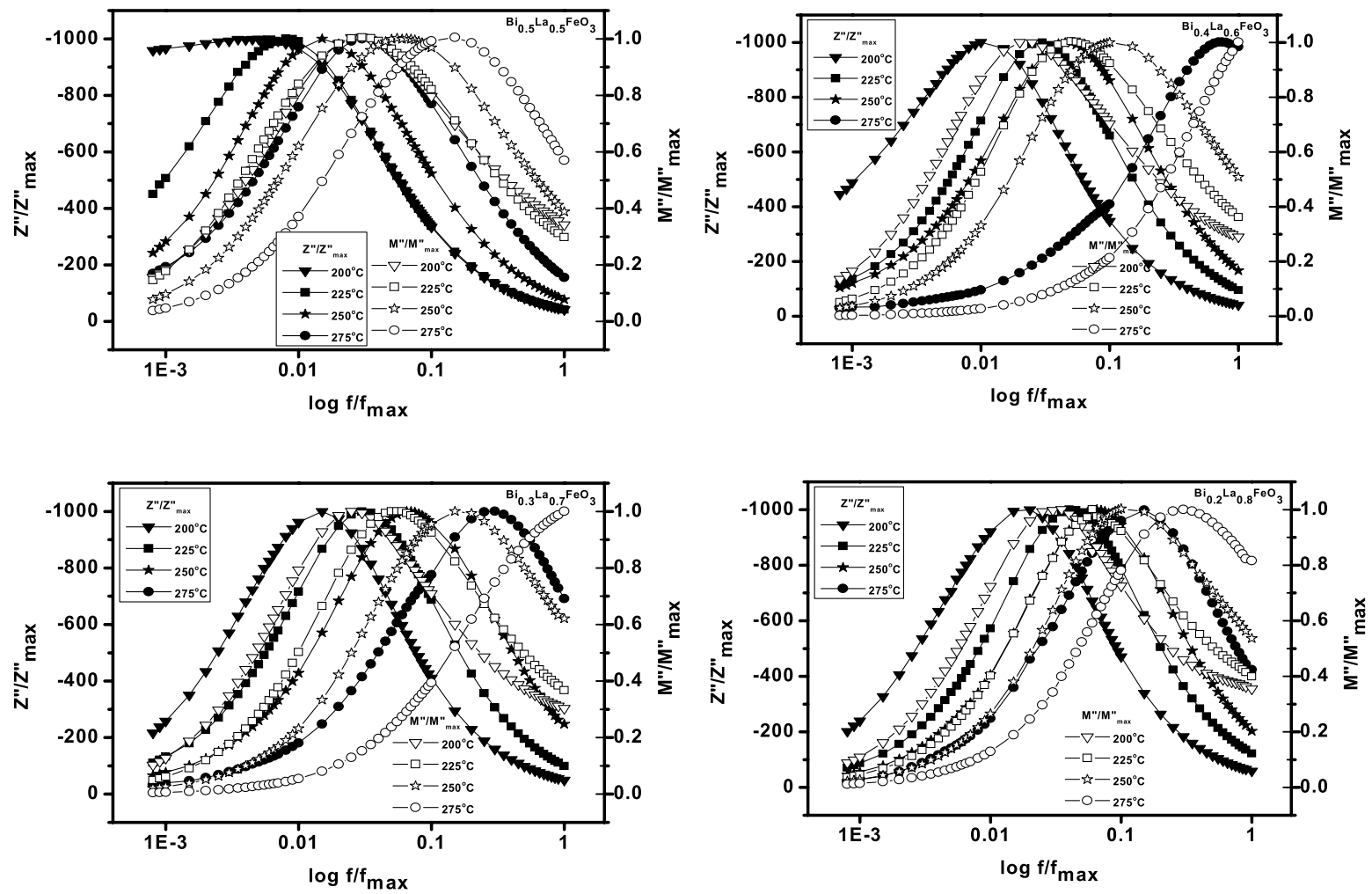

Fig. 8. Variation of $Z^{\prime \prime} / Z_{\max }^{\prime \prime}$ and $M^{\prime \prime} / M_{\max }^{\prime \prime}$ with $\log f / f_{\max }$ of $\mathrm{Bi}_{1-x} \mathrm{La}_{x} \mathrm{FeO}_{3}[x=0.5,0.6,0.7$ and 0.8$]$ at selected temperatures. 

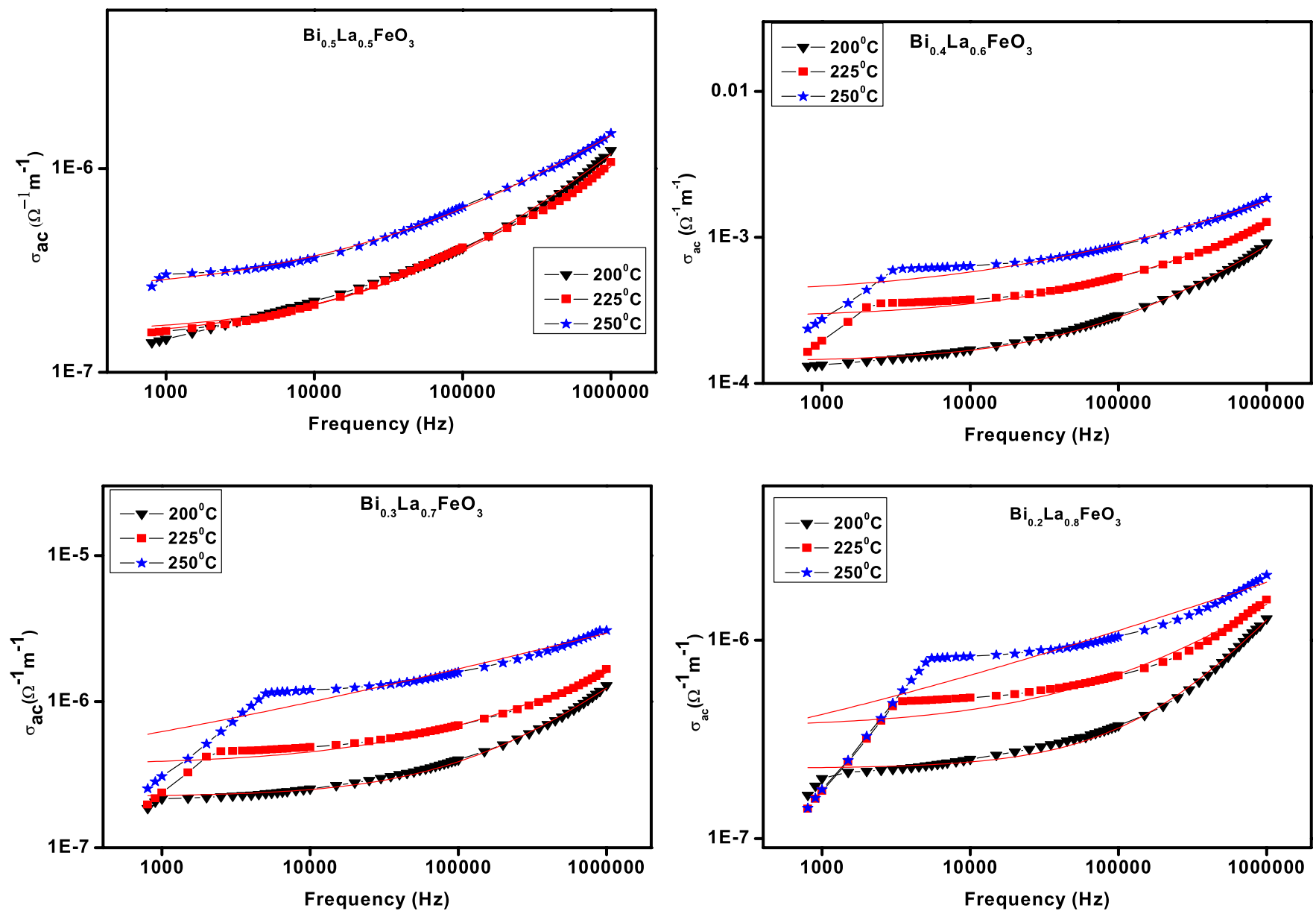

Fig. 9. Variation of ac conductivity $\left(\sigma_{\mathrm{ac}}\right)$ of $\mathrm{Bi}_{1-x} \mathrm{La}_{x} \mathrm{FeO}_{3}[x=0.5,0.6,0.7$ and 0.8$]$ with frequency at different temperatures.

to Johnscher's power law and the fitted curves are represented by the solid lines. Three regions are found, i.e., low dispersion frequency-dependent region, plateau or frequencyindependent region and high-frequency-dependent region. The solid lines in the AC conductivity spectra denote the fit of exponential data to the power law expression: $\sigma_{\mathrm{ac}}=\sigma_{o}+A \omega^{n}$, where $A$ is a parameter which has the unit of conductivity, $n$ is a dimensionless parameter and $\omega$ is the angular frequency at which the conductivity $\sigma$ was measured. The variation of $n$ with temperature suggests the type of the conduction mechanism in the material. ${ }^{25}$ For the translational motion, the value of $n$ is less than 1 , whereas for localized $n$ value is more than $1 .^{26}$ If $n<1$, charge carriers takes a translational motion with a sudden hopping. $N>1$ mean a localized hopping of the species (small hopping without leaving the neighborhood) and for $n=1$ it behaves like an ideal capacitor. ${ }^{27}$ Figure 7 shows that $n$ is temperaturedependent and decreases with increases temperature (Table 1), which follows again the small polaron model.

Figure 10 shows the variation of $\sigma_{\text {ac }}$ (bulk) with inverse of absolute temperature $10^{3} / \mathrm{T}\left(K^{-1}\right)$ of $\mathrm{Bi}_{1-x} \mathrm{La}_{x} \mathrm{FeO}_{3}[x=0.5$, $0.6,0.7$ and 0.8$]$. It is observed that the conductivity is found to be increasing with the rise in temperatures for all the materials. At high temperature, $\sigma_{\text {ac }}$ of the different frequency merges and it corresponds to dc conductivity. The activation energies are calculated for the temperature region $25-220^{\circ} \mathrm{C}$

Table 1. Fitting parameters obtained from the Jonscher power law at different temperatures.

\begin{tabular}{|c|c|c|c|c|c|c|c|c|}
\hline \multirow[b]{2}{*}{$\mathrm{T}\left({ }^{\circ} \mathrm{C}\right)$} & \multicolumn{2}{|c|}{$\mathrm{Bi}_{0.5} \mathrm{La}_{0.5} \mathrm{FeO}_{3}$} & \multicolumn{2}{|c|}{$\mathrm{Bi}_{0.4} \mathrm{La}_{0.6} \mathrm{FeO}_{3}$} & \multicolumn{2}{|c|}{$\mathrm{Bi}_{0.3} \mathrm{La}_{0.7} \mathrm{FeO}_{3}$} & \multicolumn{2}{|c|}{$\mathrm{Bi}_{0.2} \mathrm{La}_{0.8} \mathrm{FeO}_{3}$} \\
\hline & $\sigma_{\mathrm{dc}}$ & $n$ & $\sigma_{\mathrm{dc}}$ & $n$ & $\sigma_{\mathrm{dc}}$ & $n$ & $\sigma_{\mathrm{dc}}$ & $n$ \\
\hline $200^{\circ} \mathrm{C}$ & $1.56648 \mathrm{E}-4$ & 0.62 & $1.40856 \mathrm{E}-4$ & 0.71 & $2.23612 \mathrm{E}-4$ & 0.78 & $2.25881 \mathrm{E}-4$ & 0.88 \\
\hline $225^{\circ} \mathrm{C}$ & $1.42622 \mathrm{E}-4$ & 0.54 & $2.81763 \mathrm{E}-4$ & 0.56 & $3.68607 \mathrm{E}-4$ & 0.57 & $3.62167 \mathrm{E}-4$ & 0.56 \\
\hline $250^{\circ} \mathrm{C}$ & $2.44316 \mathrm{E}-4$ & 0.48 & $3.98327 \mathrm{E}-4$ & 0.44 & $1.89997 \mathrm{E}-4$ & 0.26 & $1.39424 \mathrm{E}-4$ & 0.26 \\
\hline
\end{tabular}



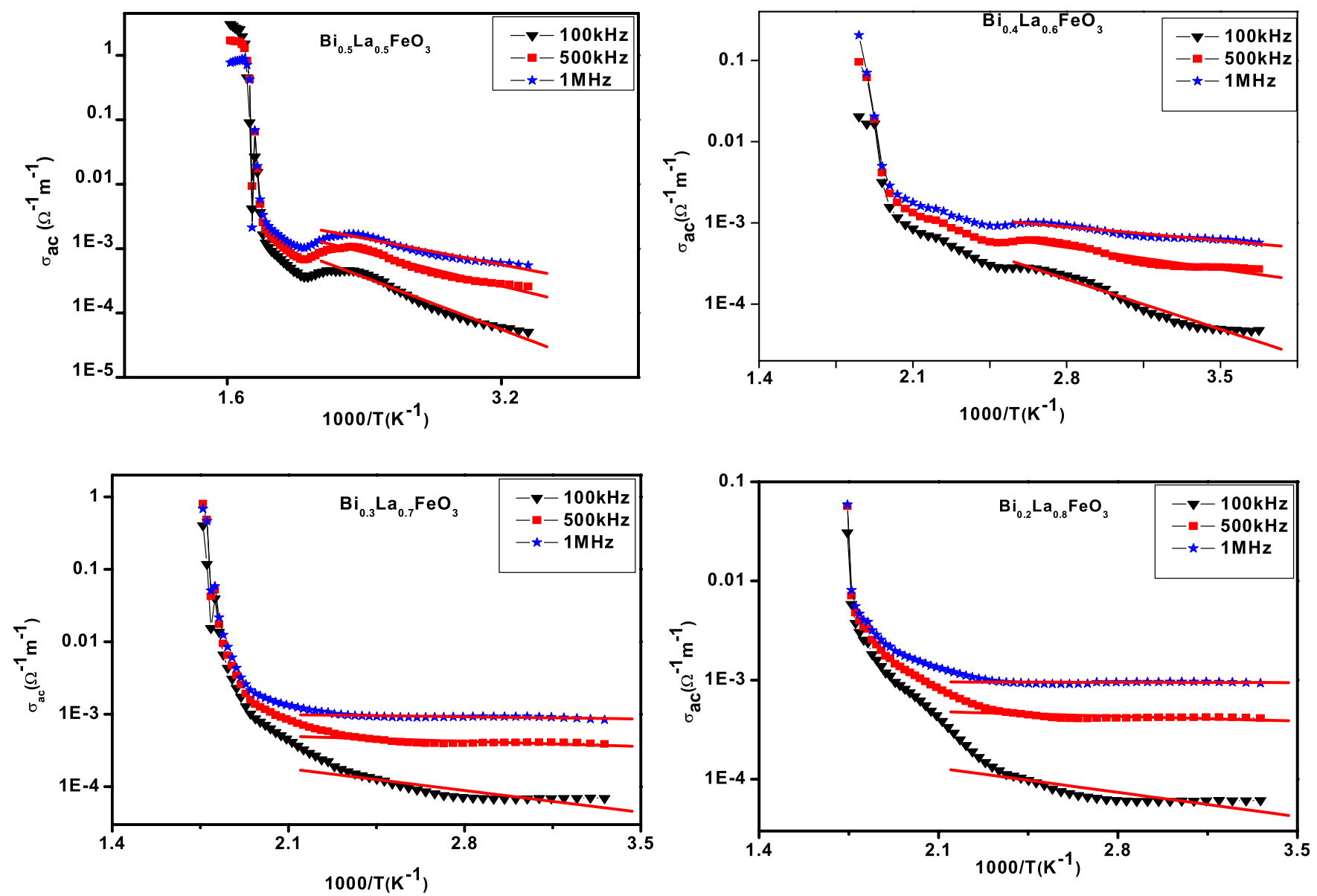

Fig. 10. Variation of ac conductivity $\left(\sigma_{\mathrm{ac}}\right)$ with $\left(10^{3} / \mathrm{T}\right)$ of $\mathrm{Bi}_{1-x} \mathrm{La}_{x} \mathrm{FeO}_{3}[x=0.5,0.6,0.7$ and 0.8$]$.

Table 2. Values of activation energies (eV) of $\mathrm{Bi}_{(1-x)} \mathrm{La}_{x} \mathrm{FeO}_{3}[x=0.5,0.6$, $0.7,0.8]$ between the temperature range $25-220^{\circ} \mathrm{C}$.

\begin{tabular}{lcccc}
\hline Frequency & $\mathrm{Bi}_{0.5} \mathrm{La}_{0.5} \mathrm{FeO}_{3}$ & $\mathrm{Bi}_{0.4} \mathrm{La}_{0.6} \mathrm{FeO}_{3}$ & $\mathrm{Bi}_{0.3} \mathrm{La}_{0.7} \mathrm{FeO}_{3}$ & $\mathrm{Bi}_{0.2} \mathrm{La}_{0.8} \mathrm{FeO}_{3}$ \\
\hline $100 \mathrm{kHz}$ & $0.96 \mathrm{eV}$ & $0.50 \mathrm{eV}$ & $0.80 \mathrm{eV}$ & $0.54 \mathrm{eV}$ \\
$500 \mathrm{kHz}$ & $0.85 \mathrm{eV}$ & $0.46 \mathrm{eV}$ & $0.71 \mathrm{eV}$ & $0.38 \mathrm{eV}$ \\
$1 \mathrm{MHz}$ & $0.72 \mathrm{eV}$ & $0.41 \mathrm{eV}$ & $0.62 \mathrm{eV}$ & $0.29 \mathrm{eV}$ \\
\hline
\end{tabular}

for all the materials. The activation energy decreases with rise in temperature (Table 2).

\section{Conclusions}

$\mathrm{Bi}_{1-x} \mathrm{La}_{x} \mathrm{FeO}_{3}[x=0.5,0.6,0.7$ and 0.8$]$ ceramics were prepared using solid state reaction technique with rhombohedral structure at room temperature. The average value of crystallite size was found to be in the range of $26 \mathrm{~nm}$. The dielectric constant of the material increased with rise in temperature. The Nyquist plot revealed the contribution of bulk effect in the materials. AC conductivity study with frequency obeys the power law of the form $\sigma_{\mathrm{ac}}=\sigma_{o}+A \omega^{n}$, with $n$ is found to be in the range $0.20-0.90$.

\section{Acknowledgments}

The authors acknowledge the financial support through DRSI of UGC under SAP for the development of research work in the School of Physics, Sambalpur University and the one of the author (BB) acknowledges to the DST under SERC Fast Track Scheme for Young Scientist (Project No. SR/FTP/PS036/2011) New Delhi, India).

\section{References}

${ }^{1}$ N. D. Mathur, F. M. Grosche, S. R. Julian, I. R. Walker, D. M. Freye, R. K. W. Haselwimmer and G. G. Lonzarich, Magnetically mediated superconductivity in heavy fermion compounds, Nature 394, 39 (1998).

${ }^{2}$ M. Fiebig, D. ThLottermoser, A. Fröhlich, V. Goltsev and R. V. Pisarev, Observation of coupled magnetic and electric domains, Nature 419, 818 (2002).

${ }^{3}$ A. N. Kalinkin and V. M. Skorikov, $\mathrm{BiFeO}_{3}$ films and single crystals as a promising inorganic material for spintronics, Russ. $J$. Inorg. Chem. 55, 1794 (2010).

${ }^{4}$ T. Wang, L. Jin, Y. Tian, L. L. Shu, Q. Hu and X. Wei, Microstructure and ferroelectric properties of $\mathrm{Nb}_{2} \mathrm{O}_{5}$-modified $\mathrm{BiFeO}_{3}-\mathrm{BaTiO}_{3}$ lead-free ceramics for energy storage, Mater. Lett. 137, 79 (2014). 
${ }^{5}$ S. V. Kiselev, R. P. Ozerov and G. S. Zhdanov, Detection of magnetic order in ferroelectric $\mathrm{BiFeO}_{3}$ by neutron diffraction, $\mathrm{Sov}$. Phys. Dokl. 7, 742 (1963).

${ }^{6}$ J. S. Kim, C. II Cheon, Y. N. Choi and P. W. Jang, Ferroelectric and ferromagnetic properties of $\mathrm{BiFeO}_{3}-\mathrm{PrFeO}_{3}-\mathrm{PbTiO}_{3}$ solid solutions, J. Appl. Phys. 93, 9263 (2003).

${ }^{7}$ S. Mohanty, A. Kumar and R. N. P. Choudhary, Studies of structural, dielectric, electrical and ferroelectric characteristics of $\mathrm{BiFeO}_{3}$ and $\left(\mathrm{Bi}_{0.5} \mathrm{~K}_{0.5}\right)\left(\mathrm{Fe}_{0.5} \mathrm{Ta}_{0.5}\right) \mathrm{O}_{3}$, J. Mater. Sci. Mater. Electron. 26, 9640 (2015).

${ }^{8}$ P. Kumar and M. Kar, Effect of excess bismuth on synthesis of bismuth ferrite, AIP Conf. Proc. 1536, 1041 (2013).

${ }^{9}$ K. Hirota, S. Wakimoto and D. E Cox, Neutron and x-ray scattering studies of relaxors, J. Phys. Soc. Jpn. 75, 111006 (2006).

${ }^{10}$ F. Azougha, R. Freer, M. Thrall, R. Cernik, F. Tuna and D. Collison, Microstructure and properties of Co-, Ni-, Zn-, Nb- and Wmodified multiferroic BiFeO3 ceramics, J. Eur. Ceram. Soc. 30, 727 (2010).

${ }^{11}$ V. A. Khomchenko, V. V. Scvartsman, P. Borisov, W. Kleemann, D. A. Kiselev, I. K. Bdikin, J. M. Vieira and A. L. Kholkin, Crystal structure and magnetic properties of $\mathrm{Bi}_{0.8}$ $\left(\mathrm{Gd}_{1-x} \mathrm{Ba}_{x}\right)_{0.2} \mathrm{FeO}_{3}(x=0,0.5,1)$ multiferroics, J. Phys D, Appl. Phys. 42, 045418 (2009).

${ }^{12}$ M. Kumar and K. Yadav, The effect of Ti substitution on magnetoelectric coupling at room temperature in the $\mathrm{BiFe}_{1-x} \mathrm{Ti}_{x} \mathrm{O}_{3}$ system, J. Phys. Condens. Matter. 18, L503 (2006).

${ }^{13}$ A. Monshi, M. R. Foroughi and M. R. Monshi, Modified Scherrer equation to estimate more accurately nano-crystallite size using XRD, World J. Nano Sci. Eng. 2, 154 (2012).

${ }^{14} \mathrm{~V}$. J. Tennery, High temperature phase transitions in $\mathrm{PbZrO}_{3}, A m$. J. Ceram. Soc. 49, 483 (1966).

${ }^{15}$ D. P. Almond and A. R. West, Impedance and modulus spectroscopy of "real" dispersive conductors, Solid State Ion. 11, 57 (1983).

${ }^{16}$ S. K. Satpathy, N. K. Mohanty, A. K. Behera, B. Behera, P. Nayak and $\mathrm{S}$. Sen, Dielectric and electrical properties of $\mathrm{BiFeO}_{3}-\mathrm{PbZrO}_{3}$ composites, J. Electron. Mater. 44, 4290 (2015).
${ }^{17}$ S. K. Satpathy, N. K. Mohanty, A. K. Behera and B. Behera, Dielectric and electrical properties of $0.5\left(\mathrm{BiGd}_{0: 05} \mathrm{Fe}_{0: 9} 5 \mathrm{O}_{3}\right)-0.5$ $\left(\mathrm{PbZrO}_{3}\right)$ composite, Mater. Sci.-Poland. 32, 59 (2014).

${ }^{18}$ T. Wang, J. Hu, H. Yang, L. Jin, X. Wei, C. Li, F. Yan and Y. Lin, Dielectric relaxation and Maxwell-Wagner interface polarization in $\mathrm{Nb}_{2} \mathrm{O}_{5}$ doped $0.65 \mathrm{BiFeO}_{3}-0.35 \mathrm{BaTiO}_{3}$ ceramics, J. Appl. Phys. 121, 084103 (2017).

${ }^{19}$ B. Behera, P. Nayak and R. N. P. Choudhary, Impedance spectroscopy study of $\mathrm{NaBa}_{2} \mathrm{~V}_{5} \mathrm{O}_{15}$ ceramic, J. Alloys Compd. 436, 226 (2007).

${ }^{20}$ T. Wang, L. Jin, C. Li, Q. Hu and X. Wei, Novel $\mathrm{BiFeO}_{3}-\mathrm{BaTiO}_{3}-$ $\mathrm{Ba}\left(\mathrm{Mg}_{2 / 3} \mathrm{Nb}_{1 / 3}\right) \mathrm{O}_{3}$ ceramics for energy storage application, J. Am. Ceram. Soc. 98, 559 (2015).

${ }^{21}$ W. Cao and R. Gerhardt, Calculation of various relaxation times and conductivity for a single dielectric relaxation process, Solid State Ion. 42, 213 (1990).

${ }^{22}$ F. Borsa, D. R. Torgeson, S. W. Martin and H. K. Patel, Relaxation and fluctuations in glassy fast-ion conductors: Wide-frequencyrange NMR and conductivity measurements, Phys. Rev. B 46, 795 (1992).

${ }^{23}$ R. Kohlrausch, Theorie des elektrischenRückstandes in der LeidenerFlasche. Pogg. Ann. Phys. Chem. 91, 179 (1854).

${ }^{24}$ S. Dutta, R. N. P. Choudhary and P. K. Sinha, Impedance spectroscopy studies on Fe3+ ion modified PLZT ceramics, Ceram. Int. 33, 13 (2007).

${ }^{25}$ S. Mohapatra, D. Pal, S. K. Ghosh and P. Pramanik, Design of superparamagnetic iron oxide nanoparticle for purification of recombinant proteins, J. Nanosci. Nanotech. 7, 1 (2007).

${ }^{26}$ V. R. Chinchamalatpure, S. A. Ghosh and G. N. Chaudhari, Synthesis and electrical characterization of $\mathrm{BaTiO}_{3}$ thin films on Si(100), Mater. Sci. Appl. 1, 04 (2010).

${ }^{27}$ E. A. Tugova, New $\mathrm{DySrAlO}_{4}$ compound synthesis and formation process correlations for $\mathrm{LnSrAlO}_{4}$ (Ln $5 \mathrm{Nd}, \mathrm{Gd}$, Dy) series, Acta Metall. Sin. 29, 450 (2016). 